TITLE:

\title{
Thermal analysis of drying process of durum wheat dough under the programmed temperature-rising conditions
}

\section{$\operatorname{AUTHOR}(S):$}

Ogawa, Takenobu; Koizumi, Satoshi; Adachi, Shuji

\section{CITATION:}

Ogawa, Takenobu ...[et al]. Thermal analysis of drying process of durum wheat dough under the programmed temperature-rising conditions. Food and Bioproducts Processing 2014, $92(1): 9-13$

ISSUE DATE:

2014-01

URL:

http://hdl.handle.net/2433/182077

\section{RIGHT:}

(C) 2013 Published by Elsevier B.V.; This is not the published version.

Please cite only the published version.; この論文は出版社版でありませ ん。引用の際には出版社版をご確認ご利用ください。 


\title{
Thermal analysis of drying process of durum wheat dough under the programmed temperature-rising conditions
}

\author{
Takenobu Ogawa, Satoshi Koizumi, Shuji Adachi* \\ Division of Food Science and Biotechnology, Graduate School of Agriculture, Kyoto University, \\ Sakyo-ku, Kyoto 606-8502, Japan \\ *Corresponding author. Tel.: +81-75-753-6286; Fax: +81-75-753-6285. \\ E-mail address: adachi@kais.kyoto-u.ac.jp (S. Adachi).
}

\begin{abstract}
The effects of temperature and moisture content on the drying rate of durum wheat pasta were examined using thermogravimetry and differential scanning calorimetry (DSC) at temperature-rising rates of 0.2 to $1.0{ }^{\circ} \mathrm{C} / \mathrm{min}$. The activation energy for the mass transfer coefficient of drying was estimated to be ca. $32 \mathrm{~kJ} / \mathrm{mol}$ at moisture contents of 0.14 $\mathrm{kg}-\mathrm{H}_{2} \mathrm{O} / \mathrm{kg}$-d.m. or higher, but increased rapidly as the moisture content dropped below this level. The conclusion temperature of the endothermic peak in the DSC and the temperature of the inflection point of the drying characteristics curve were located near the glass transition curve of the durum semolina flour.
\end{abstract}

Keywords: Durum semolina dough; Drying rate; Thermal analysis; Friedman method; Activation energy; Glass transition

\section{Introduction}

In most countries, including Japan, pasta is distributed in the dry state, which is traditionally obtained by sun drying to decrease moisture content to $0.11 \pm 0.01 \mathrm{~kg}-\mathrm{H}_{2} \mathrm{O} / \mathrm{kg}$-d.m., which is suitable for preservation. Because the process takes several days at a drying temperature of $30^{\circ} \mathrm{C}$, dried pasta is presently prepared on an industrial production scale at temperatures above $30^{\circ} \mathrm{C}$, with the production classified into low-temperature, high-temperature and very high-temperature (VHT) processes at maximum temperatures of ca. 50,70 and $85^{\circ} \mathrm{C}$, respectively, and drying times of ca. 20, 13 and $6 \mathrm{~h}$, respectively. Among these, the VHT process is most frequently adopted by manufacturers because of the short production time. Recently, an ultrahigh temperature process has been demonstrated at a drying temperature of $95^{\circ} \mathrm{C}$.

A typical drying curve for pasta, which reflects the transient change in moisture content, is concave, i.e., the moisture content rapidly decreases during the early stages of drying, and gradually decelerates to become very low at later stages (Ogawa et al., 2012). As a result, a large part of the entire drying period is occupied by drying the low-moisture regime, suggesting that any increase in drying rate in this region will reduce drying time.

During drying, pasta transforms from a rubbery state to a glassy state with a concomitant decrease in moisture content (Xing et al., 2007). A similar transition has been reported for drying of strawberries (Moraga et al., 2004), tomatoes (Goula et al., 2008), apricots (Mrad et al., 2012), wheat (Cuq and Icard-Vernière, 2001) and starch (Mizuno et al., 1998; Liu et al., 2009). The drying process can usually be described by Fick's law of diffusion (Aversa et al., 2007; Mihoubia and Bellagi, 2008; Curcio et al., 2008; Tripathy and Kumar, 2009; Pavón-Melendez et al., 2002; Akiyama and Hayakawa, 2000). Unfortunately, near the glass transition point of durum wheat flour, the law 
cannot exactly predict drying behavior of pasta because of the occurrence of non-Fickian phenomena (Xing et al., 2007; Singh et al., 2004). As a consequence, it is difficult to precisely predict the drying behavior in the low moisture-content region where this glass transition occurs. For rational design of the pasta drying process, knowledge of how the drying rate varies over a wide range of temperatures and moisture contents is required.

To evaluate constant drying rates and mass-transfer coefficients in the regime where rates decrease, we previously analyzed drying processes based on a decrease in weight of the dough, as measured using a thermogravimeter at constant temperatures and humidities (Ogawa et al., 2012). The change in moisture content of pasta that was dried in a laboratory-scale oven under programmed conditions, i.e., simulating the changes in temperature and humidity in the industrial production of pasta, could be successfully predicted using the constant-drying rates and mass-transfer coefficients obtained. This observation indicated thermogravimetric analysis of dough to be effective for studying the physical phenomena underlying drying of pasta.

The objective of this study is to examine the effects of temperature and moisture content on the drying behavior of pasta. The drying rate of durum wheat dough was measured using a thermogravimeter at various temperature-rising rates to estimate the dependence of the activation energy on moisture content. Differential scanning calorimetric measurements (DSC) were also performed under the same conditions as the thermogravimetric ones. Based on these measurements, the effects of the temperature and the moisture content on the drying rate of pasta were discussed.

\section{Materials and Methods}

\subsection{Sample preparation}

Durum wheat semolina with a moisture content of $0.163 \mathrm{~kg}-\mathrm{H}_{2} \mathrm{O} / \mathrm{kg}$-d.m. was supplied by Nisshin Foods, Inc. (Tokyo, Japan). The durum wheat semolina (100 g-w.m.) was mixed with water (30 g) using an SKH-A100 mixer (Tiger Corporation, Osaka, Japan) for $5 \mathrm{~min}$, after which the mixture stood at room temperature for at least $3 \mathrm{~h}$ to produce the dough.

\subsection{Thermogravimetry}

Following our previously reported methods (Ogawa et al., 2012), the hydrated semolina (20 $\mathrm{mg}$ ) was pressed into a single-sided open platinum cell. The weight loss during drying was measured using a TGA-50 thermogravimeter (Shimadzu, Kyoto, Japan) under a flow of dry nitrogen at 20 $\mathrm{mL} / \mathrm{min}$. Before drying, dry nitrogen gas was fed for $30 \mathrm{~min}$. Because the dry nitrogen was flowing, the relative humidity of the dough surface was assumed to be $0 \%$. The weight loss of the sample was measured from room temperature to $100^{\circ} \mathrm{C}$ under linearly rising-temperature conditions of 0.2 to $1.0{ }^{\circ} \mathrm{C} / \mathrm{min}$, and the sample was dried at $135^{\circ} \mathrm{C}$ for $5 \mathrm{~h}$ to estimate its bone-dry weight. The drying rate was evaluated by differentiating the weight loss with time at various moisture contents using Origin 8.1J (OriginLab, MA, USA). Measurements were performed at least twice to confirm reproducibility.

\subsection{Activation energy}

Because the change in sample weight was measured under a flow of dry nitrogen, the equilibrium amount of water sorbed onto the flour should be zero. Therefore, the fraction of water remaining on the flour, $Y$, was calculated by the following equation:

$$
Y=w / w_{0}
$$

where $w_{0}$ and $w$ are the initial moisture content and the moisture content at time $t$, respectively.

The activation energy, $E$, at a specific $Y$ value was estimated by an isoconversion method using the drying data obtained at various temperature-rising rates. Among the various methods available (Ozawa, 1992), we adopted the method of the differential type proposed by Friedman (1964). The change in the $Y$ value with time, $\mathrm{d} Y / \mathrm{d} t$, corresponding to the drying rate, can then be expressed by Eq. (2):

$$
\mathrm{d} Y / \mathrm{d} t=k f(Y)
$$

where $f(Y)$ is a kinetic function concerning the 


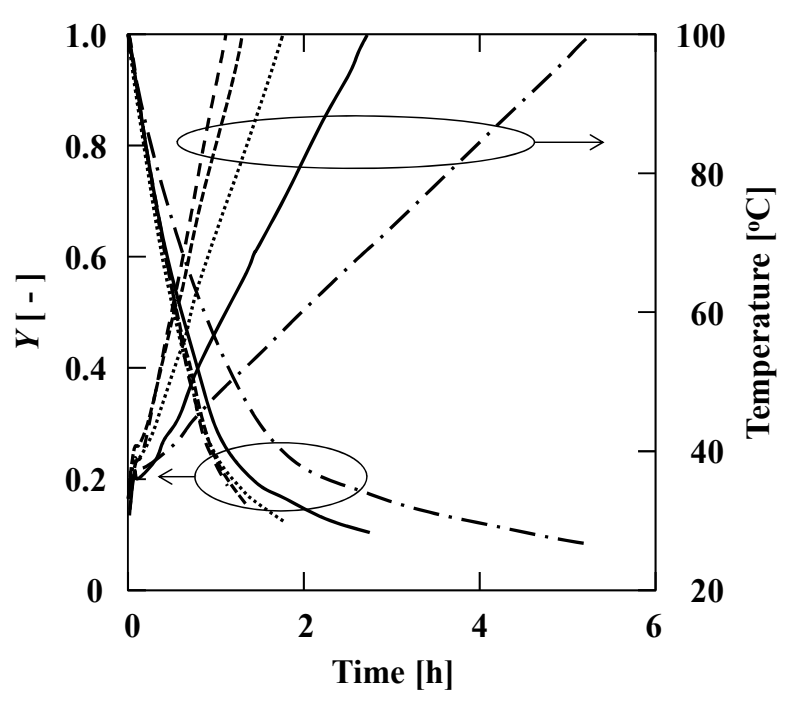

Fig. 1 - Drying curves under programmed temperature-rising conditions of $(--) 0.2,(-) 0.4,(\cdots)$ 0.6 , (---) 0.8 and $(--) 1.0{ }^{\circ} \mathrm{C} / \mathrm{min}$. The parameter $Y$ (ordinate axis) indicates the fraction of water remaining on the flour.

driving force for drying, and $k$ is the mass transfer coefficient. The temperature dependence of this coefficient, $k$, can be expressed by the Arrhenius equation:

$$
k=k_{0} \exp (-E / R T)
$$

where $k_{0}$ is the frequency factor, $E$ is the activation energy, $R$ is the gas constant, and $T$ is the absolute temperature. Substituting Eq. (3) into Eq. (2) gives the following equation:

$$
\ln (\mathrm{d} Y / \mathrm{d} t)=-E / R T+\ln \left[k_{0} f(Y)\right]
$$

To estimate the activation energy, the $\mathrm{d} Y / \mathrm{d} t$ values at a specific value of $Y$ were evaluated by numerical differentiation of the drying curve obtained at different temperature-rising rates, and plotted versus $1 / T$ on a semi-logarithmic scale.

\subsection{Differential scanning calorimetry}

DSC analysis was performed under the same conditions as those of the thermogravimetric (TG) analysis, using a DSC-50 (Shamadzu, Kyoto, Japan). Measurements were performed at least twice to confirm reproducibility.

\section{Results and Discussion}

3.1. Thermogravimetric analysis of the drying process

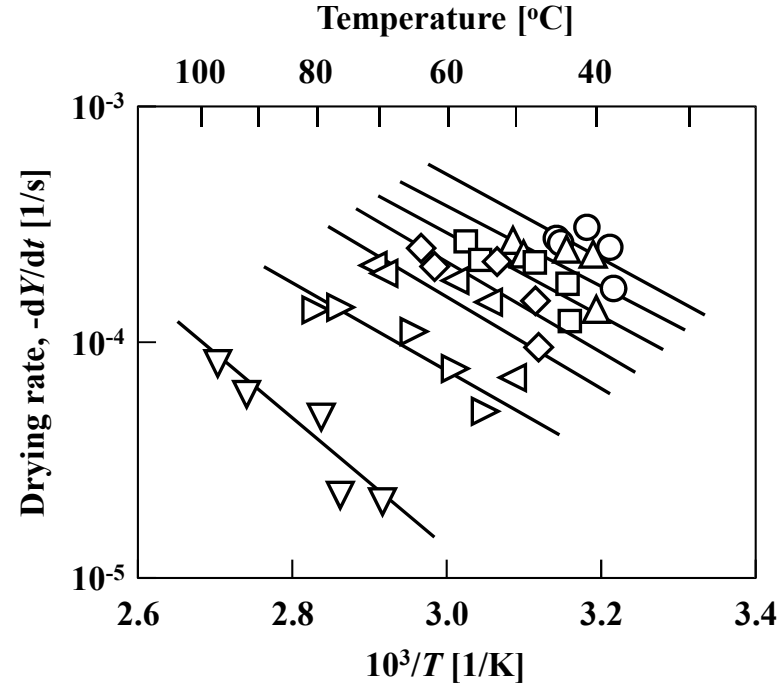

Fig. 2 - Temperature dependences of the drying rate at the fractions of water remaining on the flour, $Y$, of $(\bigcirc)$ $0.8,(\triangle) 0.7,(\square) 0.6,(\diamond) 0.5,(\triangleleft) 0.4,(\triangleright) 0.3$ and $(\nabla)$ 0.2 .

Figure 1 shows the change in the fraction of water remaining on the flour, i.e., $Y$, and the temperature during drying at the different temperature-rising rates, as measured by TG analysis.

All drying curves under the temperature-rising conditions were concave and similar to those under isothermal drying conditions (Ogawa et al., 2012). The drying rate was higher at increased temperature-rising rates, and became increasingly low at low moisture contents.

The applicability of Eq. (4) was examined by plotting the value of $\mathrm{d} Y / \mathrm{d} t$ versus $1 / T$ on a semi-logarithmic scale, as shown in Figure 2 for

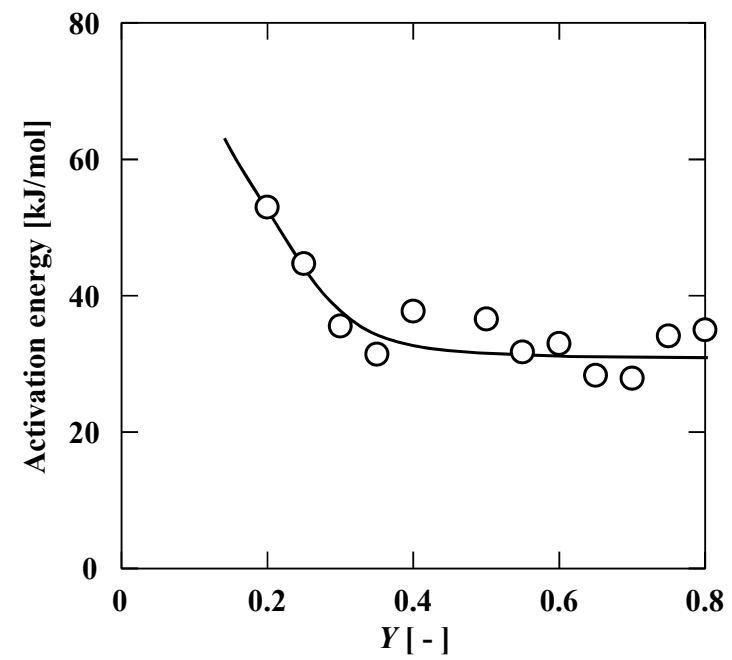

Fig. 3 - Effect of the fraction of water remaining on the flour, $Y$, on the activation energy, $E$. 
number of $Y$ values. For each $Y$ value, the points were fitted to a straight line to obtain $E$ and $k_{0} f(Y)$.

Figure 3 shows the estimated $E$ values, plotted against $Y$ values ranging from 0.2 to 0.8 . The $E$ values at $Y$ values above 0.35 , corresponding to a moisture content of $0.14 \mathrm{~kg}-\mathrm{H}_{2} \mathrm{O} / \mathrm{kg}$-d.m., were fairly constant at $32 \mathrm{~kJ} / \mathrm{mol}$, while they were larger at $Y$ values below 0.35 . For the fraction of water remaining on the flour of $Y=0.2$, the activation energy was $E=53.0 \mathrm{~kJ} / \mathrm{mol}$. These facts indicate the drying rates to markedly decrease in the later stages of drying.

\subsection{DSC measurements}

Figure 4 shows the DSC curves at various temperature-rising rates. All curves exhibited endothermic peaks. Because such peaks were observed at low moisture contents, it was reasoned that they resulted from the enthalpy recovery of amorphous starch rather than from gelatinization. This assumption appeared to be supported by the fact that the endothermic peak was broader at lower temperature-rising rate and that the structure of amorphous starch was more relaxed because of the longer aging time at lower rate. Typically, using a hermetic cell, the glass transition can be observed at temperatures above the endothermic peak during the early stage of enthalpy relaxation in DSC (Kawai et al., 2003). In this study, the glass

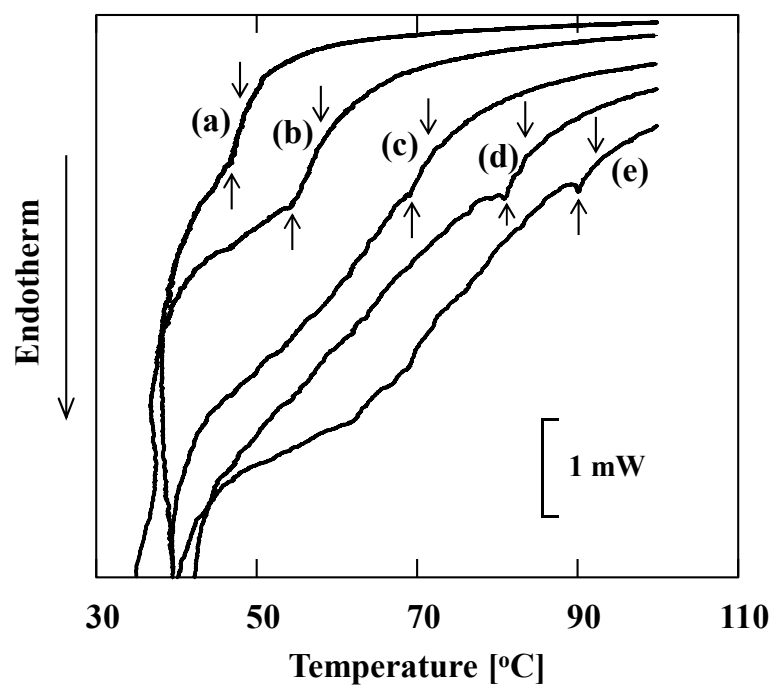

Fig. 4 - DSC curves at (a) 0.2, (b) 0.4, (c) 0.6, (d) 0.8 and (e) $1.0{ }^{\circ} \mathrm{C} / \mathrm{min}$ during drying. The upward- and downward-facing arrows show the peak and conclusion of the endotherms, respectively.

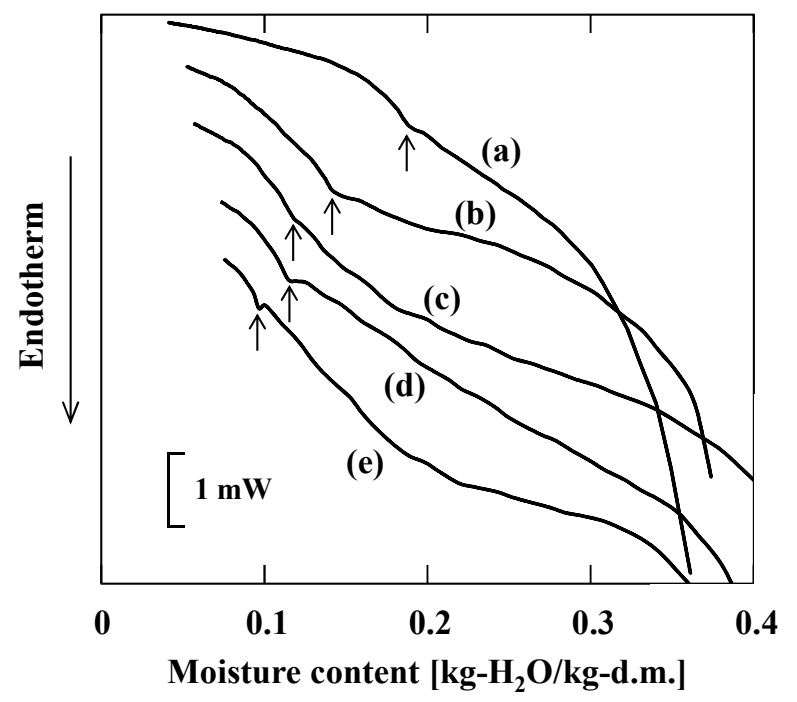

Fig. 5 - Relationship between moisture content and endotherm during drying, as determined by DSC and TG at (a) 0.2 , (b) 0.4 , (c) 0.6 , (d) 0.8 and (e) $1.0{ }^{\circ} \mathrm{C} / \mathrm{min}$. The arrows indicate the location of the endothermic peaks.

transition could not clearly be observed because measurements were carried out using an open cell and the moisture content gradually decreased. However, a slightly endothermic shoulder after the endothermic peak seemed to suggest the occurrence of a glass transition.

The DSC curves re-drawn as a function of the moisture content, based on the TG and DSC measurements results, are shown in Figure 5. Endothermic peaks were observed between moisture contents of 0.10 to $0.20 \mathrm{~kg}-\mathrm{H}_{2} \mathrm{O} / \mathrm{kg}$-d.m.,

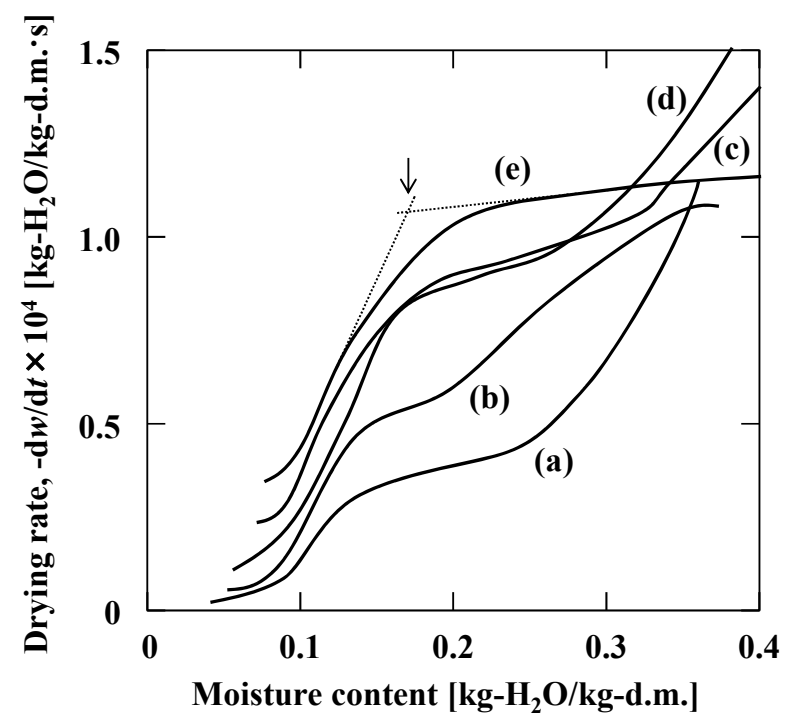

Fig. 6 - Drying characteristics curves under programmed rising temperature conditions at (a) 0.2 , (b) 0.4 , (c) 0.6, (d) 0.8 and (e) $1.0{ }^{\circ} \mathrm{C} / \mathrm{min}$. The arrow indicates the inflection point of the decreasing drying rate of 1.0 ${ }^{\circ} \mathrm{C} / \mathrm{min}$. 


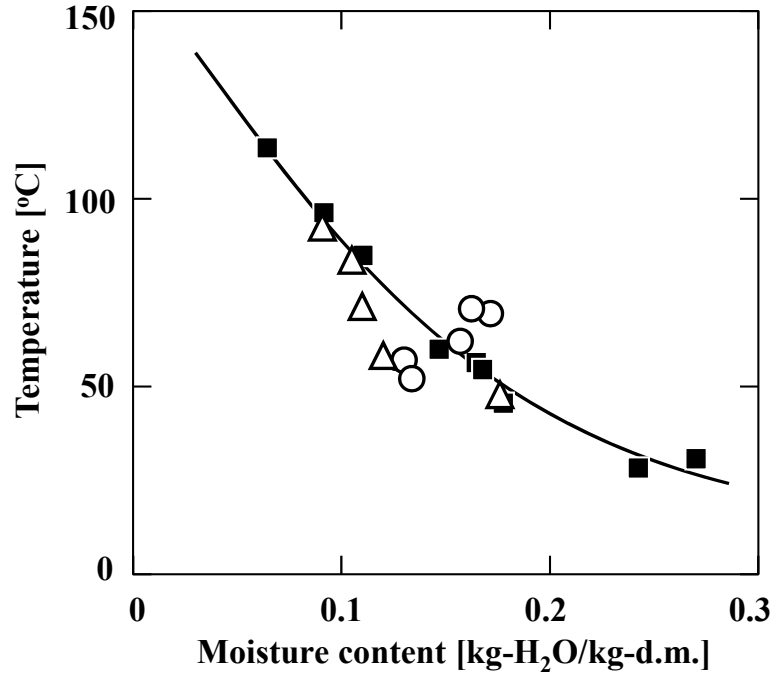

Fig. 7 - Relationship between the moisture content and (O) the temperature of the inflection points of the drying characteristic curves, as well as those between $(\triangle)$ the conclusion of the endothermic peaks in DSC or ( $\square$ ) the glass transition temperature. The glass transition temperature was adopted from literature ( $\mathrm{Cuq}$ and Icard-Vernière, 2001).

with the peak shifting to lower moisture contents for the drying process at higher temperature-rising rates.

\subsection{Effect of moisture content on the drying rate}

The drying rate is plotted against moisture content in Figure 6 for all temperature-rising rates, where it was observed that the constant drying rate was higher at higher temperature-rising rates. This result is ascribed to the fact that the temperature at a given moisture content is higher at higher temperature-rising rates. The drying rate markedly decreased at moisture contents of 0.15 to 0.20 $\mathrm{kg}-\mathrm{H}_{2} \mathrm{O} / \mathrm{kg}$-d.m. or lower, where roughly corresponded to that moisture content where activation energy started to increase (Figure 3 ).

Figure 7 shows the relationship between the conclusion temperature of the endothermic peak in the DSC measurements and moisture content, as well as those between the temperature where the drying rate started to decrease rapidly or the glass transition temperature of durum semolina flour with moisture content (Cuq and Icard-Vernière, 2001). The plot for the conclusion temperatures of the endothermic peaks coincides with the glass transition curve, which strongly suggests the glass transition to occur after the endothermic peak. The plots for the temperature of the inflection points of the drying characteristics curves (Figure 6) were located near the glass transition curve as well. Therefore, the glass transition of dough from the rubbery to the glassy state produced a rapid increase in activation energy and a rapid decrease in drying rate.

\section{Conclusions}

The activation energy of the mass transfer coefficient for the drying of durum semolina dough was determined to be ca. $32 \mathrm{~kJ} / \mathrm{mol}$ at a moisture content of $0.14 \mathrm{~kg}-\mathrm{H}_{2} \mathrm{O} / \mathrm{kg}-\mathrm{d} . \mathrm{m}$. or higher, yet markedly increased as the moisture content dropped below $0.14 \mathrm{~kg}-\mathrm{H}_{2} \mathrm{O} / \mathrm{kg}$-d.m. TG and DSC measurements indicated an endothermic peak resulting from enthalpy recovery of amorphous starch at moisture contents of 0.10 to 0.20 $\mathrm{kg}-\mathrm{H}_{2} \mathrm{O} / \mathrm{kg}$-d.m. A large decrease in drying rate was, furthermore, observed at moisture contents of 0.15-0.20 kg- $\mathrm{H}_{2} \mathrm{O} / \mathrm{kg}$-d.m. or below. Both the conclusion temperature of the endothermic peak in the DSC measurements and the temperature of the inflection points of the drying characteristics curves were located near the glass transition curve of durum semolina flour. In summary, these observations indicated the glass transition to play an important role in the drying rate.

\section{Acknowledgments}

This study was carried out during the project study of 'The Cereal Science Consortium by the Graduate School of Agriculture, Kyoto University, and the Nisshin Seifun Group, Inc'. This study was partly supported by a grant from the Japan Society for the Promotion of Science for a research fellow (T.O.).

\section{References}

Akiyama, T., Hayakawa, K., 2000. Heat and moisture transfer and hygrophysical changes in elastoplastic hollow cylinder-food during drying. J. Food Sci. 65, 315-323.

Aversa, M., Curcio, S., Calabrò, V., Iorio, G., 2007. 
An analysis of the transport phenomena occurring during food drying process. J. Food Eng. 78, 922-932.

Cuq, B., Icard-Vernière, C., 2001. Characterisation of glass transition of durum wheat semolina using modulated differential scanning calorimetry. J. Cereal Sci., 33, 213-221.

Curcio, S., Aversa, M., Calabrò, V., Iorio, G., 2008. Simulation of food drying: FEM analysis and experimental validation. J. Food Eng. 87, 541-553.

Friedman, H.L., 1964. Kinetics of thermal degradation of char-forming plastics from thermogravimetry. Application to a phenolic plastic. J. Polym. Sci. C 6, 183-195.

Goula, A.M., Karapantsios, T.D., Achilias, D.S., Adamopoulos, K.G., 2008. Water sorption isotherms and glass transition temperature of spray dried tomato pulp. J. Food Eng. 85, 73-83.

Kawai, K., Kim, Y.J., Suzuki, T., 2003. Estimation of the stability of glassy product by thermal analysis. Jpn. J. Thermophys. Prop. 17, 114-127.

Liu, P., Yu, L., Liu, H., Chen, L., Li, L., 2009. Glass transition temperature of starch studied by a high-speed DSC. Carbohydr. Polym. 77, 250-253.

Mihoubia, D., Bellagi, A., 2008. Two-dimensional heat and mass transfer during drying of deformable media. Appl. Math. Model. 32, 303-314.

Mizuno, A., Mitsuiki, M., Motoki, M., 1998. Effect of crystallinity on the glass transition temperature of starch. J. Agric. Food Chem. 46, 98-103.

Moraga, G., Martinez-Navarrete, N., Chiralt, A., 2004. Water sorption isotherms and glass transition in strawberries: influence of pretreatment. J. Food Eng. 62, 315-321.

Mrad, N.D., Bonazzi, C., Boudhrioua, N., Kechaou, N., Courtois, F., 2012. Influence of sugar composition on water sorption isotherms and on glass transition in apricots. J. Food Eng. 111, 403-411.

Ogawa, T., Kobayashi, T., Adachi, S., 2012. Prediction of pasta drying process based on a thermogravimetric analysis. J. Food Eng. 111, 129-134.

Ozawa, T., 1992. Estimation of activation energy by isoconversion methods. Thermochim. Acta 203, 159-165.

Pavón-Melendez, G., Hernández, J.A., Salgado, M.A., Garcia, M.A., 2002. Dimensionless analysis of the simultaneous heat and mass transfer in food drying. J. Food Eng. 51, 347-353.

Singh, P.P., Maier, D.E., Cushman, J.H., Campanella, O.H., 2004. Effect of viscoelastic relaxation on moisture transport in foods. Part II: sorption and drying of soybeans. J. Math. Biol. 49, 20-34.

Tripathy, P.P., Kumar, S., 2009. A methodology for determination of temperature dependent mass transfer coefficients from drying kinetics: Application to solar drying. J. Food Eng. 90, 212-218.

Xing, H., Takhar, PS., Helms, G., He, B., 2007. NMR imaging of continuous and intermittent drying of pasta. J. Food Eng. 78, 61-68. 